\title{
Human skeletal muscle cytosols are refractory to cytochrome $c$-dependent activation of type-Il caspases and lack APAF-1
}

\author{
David H. Burgess ${ }^{1}$, Michael Svensson ${ }^{1,2}$, Tiziana Dandrea ${ }^{1}$, \\ Karina Grönlund ${ }^{1}$, Folke Hammarquist ${ }^{3}$, Sten Orrenius ${ }^{1}$ and \\ Ian A. Cotgreave*,1 \\ 1 Institute of Environmental Medicine, Karolinska Institute, Box 210, S-17177 \\ Stockholm, Sweden \\ 2 Department of Physiology and Pharmacology, Karolinska Institute, Box 5626, \\ 11486 Stockholm, Sweden; \\ ${ }^{3}$ Department of Surgery, St. Gôrans Hospital, Stockholm, Sweden \\ * corresponding author: I.A. Cotgreave, Institute of Environmental Medicine, \\ Karolinska Institute, Box 210, S-17177 Stockholm, Sweden \\ e-mail: ian.cotgreave@imm.ki.se
}

Received 26.10.98; revised 25.11.98; accepted 10.12.98

Edited by: G. Melino

\begin{abstract}
Apoptotic regulatory mechanisms in skeletal muscle have not been revealed. This is despite indications that remnant apoptotic events are detected following exercise, muscle injury and the progression of dystrophinopathies. The recent elicitation of a cytochrome $c$-mediated induction of caspases has led to speculation regarding a cytochrome $c$ mechanism in muscle. We demonstrate that cytosols from skeletal muscle biopsies from healthy human volunteers lack the ability to activate type-II caspases by a cytochrome c-mediated pathway despite the confirmed presence of both procaspase-3 and -9. This was not due to the presence of an endogenous inhibitor, as the muscle cytosols enhanced caspase activity when added to a control cytosol, subsequently activated by cytochrome $c$ and dATP. In addition, we demonstrate that muscle cytosols lack the apoptosis protease activator protein-1 (APAF-1), both at the protein and mRNA levels. These data indicate that human skeletal muscle cells will be refractory to mitochondrial-mediated events leading to apoptosis and thus can escape a major pro-apoptotic regulatory mechanism. This may reflect an evolutionary adaptation of cell survival in the presence of the profusion of mitochondria required for energy generation in motility.
\end{abstract}

Keywords: skeletal muscle; type II caspases; cytochrome $c$; APAF-1

Abbreviations: PCD, programmed cell death; APAF-1, apoptosis protease activating factor-1; Cyt $c$, cytochrome $c$; CPP 32 , caspase 3; DEVD, Asp-Glu-Val-Asp; DEVD-AMC, DEVD-amino-4-mthylcoumarin; DEVD-CHO, DEVD-aldehyde; G3PDH, glyceraldehyde3-phosphate dehydrogenase; PTP, permeability transition pore; PMSF, phenyl methylsulphonyl fluoride; DTT, dithiothreitol; acLLnL, calpeptin; BCA, bichinconinic acid

\section{Introduction}

The mechanisms underlying the regulation of skeletal muscle proliferation and maintenance are of considerable interest to both clinical medicine and in sports science. Programmed cell death (PCD), by apoptosis, is emerging as a fundamental process in the regulation of normal tissue development and homeostasis. ${ }^{1}$ Concordantly, it can be predicted that programmed cell death may be of importance in both adaptive and proliferative responses to exercise and muscle injury as well as the progression of dystrophinopathies. An aberrant regulation of apoptosis has been associated with a number of human disease states including cancer, HIV/AIDS and a number of auto-immune and neurodegenerative disorders. ${ }^{1}$ In opposition to the considerable body of knowledge accumulated on the regulation of apoptosis in immunecompetent cells, the executioner process of PCD is poorly understood in solid tissues such as skeletal muscle. Using morphological criteria and relatively simple diagnostic assays such as immunohistochemical staining, recent studies have indicated that apoptosis may be involved in skeletal muscle pathophysiologies associated with a number of degenerative neuromuscular diseases. ${ }^{2}$ Other researchers have indicated that an apoptotic mechanism is part of an adaptive response in skeletal and cardiac muscle during physical exercise. ${ }^{3}$ One of the major limitations restricting an understanding in this area lies in the nature of the muscle cells themselves. Fully differentiated syncytial long cells are extremely large and multi-nucleated, containing up to 100 nuclei. Some studies have shown that the number of myonuclei in a single muscle cell or fibre decreases as an adaptive response following reductions in neuromuscular activation and/or loading. ${ }^{4}$ This observation had led to the proposition that apoptosis in skeletal muscle may be primarily characterised by programmed nuclear death ${ }^{5}$ rather than as deletion of the entire muscle cell. Despite this, there is a void in the characterisation of any biochemical mechanisms regulating PCD and apoptosis in skeletal muscle.

A central component of the signal mechanism leading to apoptotic cell deletion is the activation of a series of procaspase proteases. ${ }^{6}$ In terms of muscle cells, the only available data on the caspases comes from cardiac myocytes where bouts of ischaemia-reperfusion injury induce the accumulation of CPP32 (caspase-3) in the I/R region. ${ }^{7}$ It is now established that holocytochrome $c$ (holoCyt- $c$ ) is released from the mitochrondrion following membrane depolarisation and/or poration and that this is possibly one of the most universal triggering events during the regulation of apoptosis. ${ }^{8,9}$ Wang and co-workers have shown that procaspase- 9 is activated by the addition of holoCyt- $c$ and dATP to S-100 cellular cytosols. ${ }^{10}$ This same group has also demonstrated that the minimum cytosolic 
contribution to this activation includes the above three components plus the $130 \mathrm{kDa}$ protein APAF-1. ${ }^{11}$ Following its activation, the procaspase targets of caspase- 9 include procaspase- $3^{12}$ which can serve as a PCD executioner protease cleaving and possibly activating both other procaspases as well as other enzymatic and structural proteins. ${ }^{6,13}$ In this manner S-100 cytosols from various cell sources can be shown to generate specific type-II caspase activity (DEVD-ase) dependent upon holoCyt- $c$ and dATP additions. ${ }^{10,14}$

Therefore, we choose to determine if the capacity of human skeletal muscle cytosols qualitatively paralleled the holoCyt-c/dATP-mediated activation of type-II caspases seen in haematopoietic cells. Our observations suggest that these cytosols were devoid of holoCyt- $c$-inducible caspase activity and that this result is indicative of a necessary endogenous mechanism for the regulation and maintainance of skeletal muscle integrity.

\section{Results}

In the present study, we show that direct holoCyt-c/dATPmediated activation of human skeletal muscle S-100 cytosols does not generate any DEVDase activity (Figure 1). This was observed in nine biopsy samples involving muscle obtained from regularly exercising healthy individuals of which six are represented in Figure 1. To exclude the possibility that an

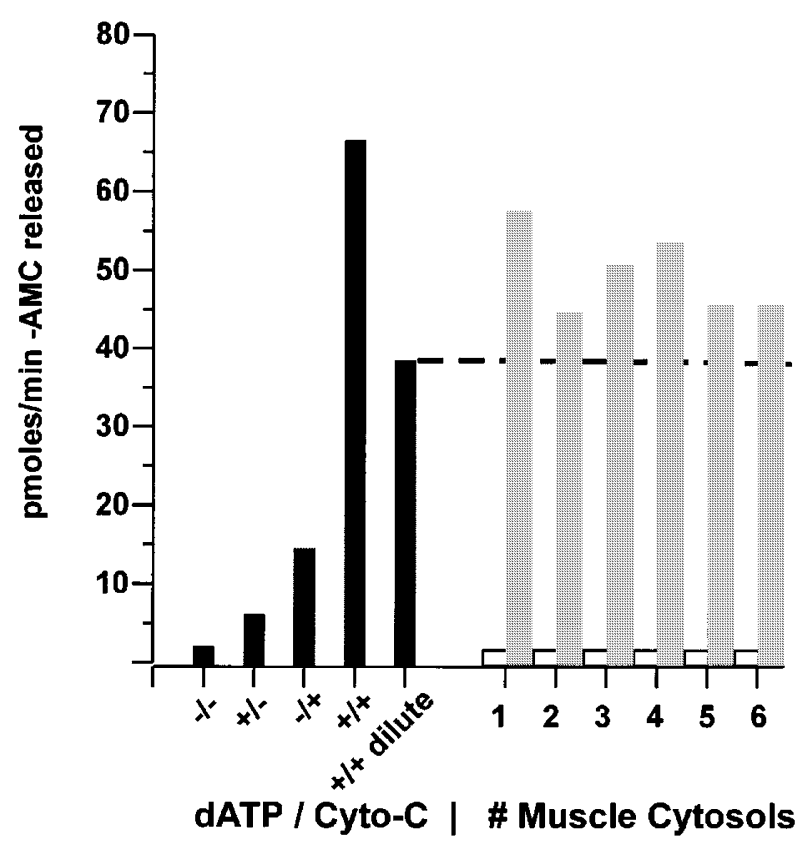

Figure 1 The direct and indirect activation of muscle cytosols. As a control the direct in vitro activation of type-II caspases in Jurkat cytosols was accomplished by adding dATP and/or holoCyt- $c$ followed by a $30^{\circ} \mathrm{C}$ incubation. The caspase activity was evaluated as pmoles/min - AMC release from DEVDAMC (black bars). The ' $+/+$ dilute' group consists of a $5 \mu \mathrm{l} \mathrm{S-100} \mathrm{buffer} \mathrm{control}$ added to the 't/+' group prior to incubation. The direct activtion of muscle cytosols was performed as for the Jurkat cytosols (open bars). The indirect activation of muscle cytosols was accomplished by adding $5 \mu \mathrm{l}(\sim 10 \mu \mathrm{g}$ protein) of the same muscle samples to separate $20 \mu$ l Jurkat $+/+$ groups (grey bars). The dotted line indicates the response of the dilution control inhibitor of the holoCyt-c/dATP activation system is present in muscle cytosols, they were added to an Jurkat T Cell-derived S-100 cytosol prior to activation. In all cases, compared with buffer alone, the generation of inherent DEVDase activity was detected (Figure 1). This suggests that skeletal muscle cytosols do not contain an endogenous inhibitor of the direct activation of type II caspases by holoCyt-c/dATP.

We then assessed the relative contribution of musclecytosol procaspases to the holoCyt-c/dATP-mediated Jurkat S-100 cytosol activation, based on a proteinnormalised twofold dilution series (Figure 2a). This was directly compared with Jurkat cytosol and bovine serum
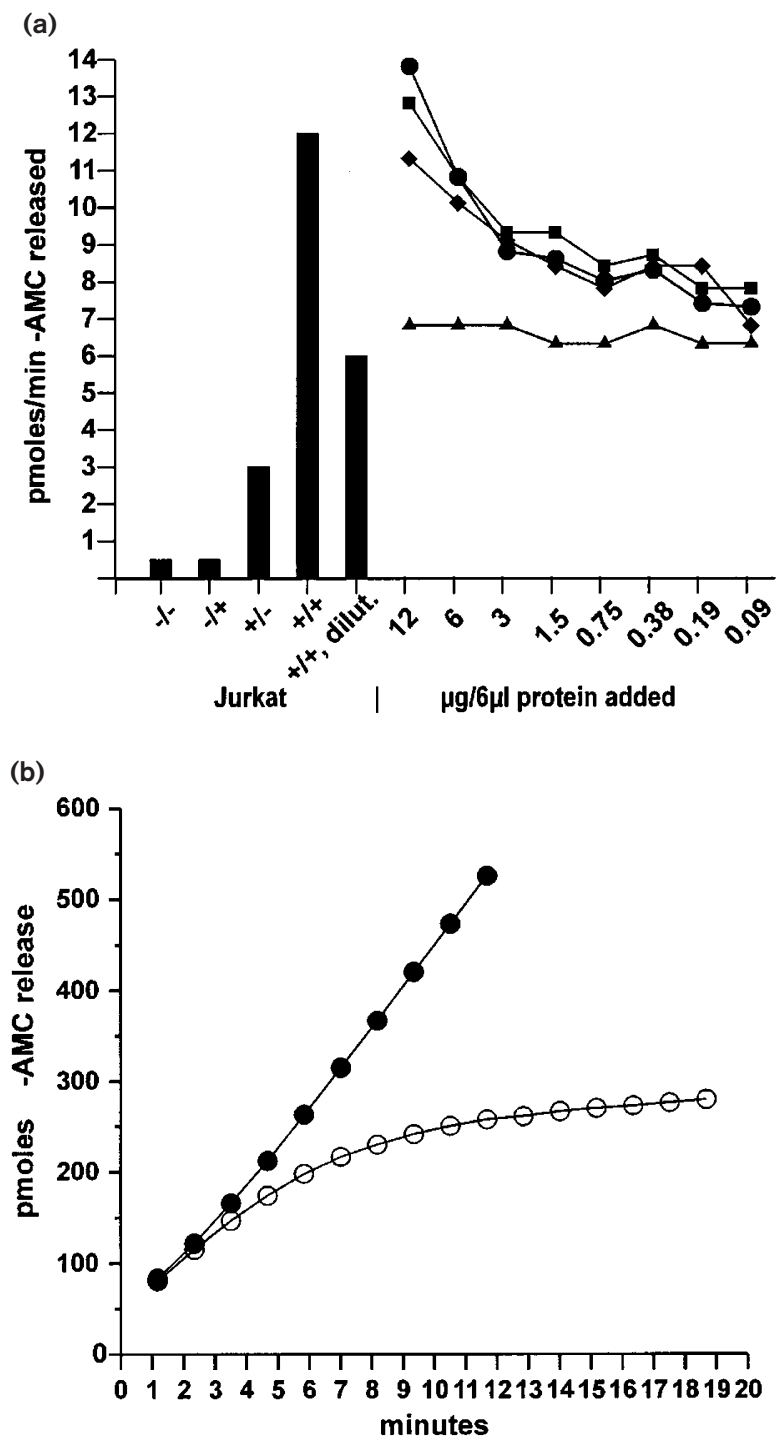

Figure 2 (a) The relative contribution of procaspases in muscle cytosols. The direct activation of Jurkat cytosol was performed as in Figure 1 (black bars). Jurkat (O) or muscle (no.4-, no.6- $\$$ ) cytosols and a BSA solution in S-100 buffer $(\mathbf{A})$ were diluted such that a 61 addition supplemented the indicated protein amount to a Jurkat S-100 cytosol prior to a '+/+' group activation. (b) The kinetics of inhibition using DEVD-cho. Picomoles of $-\mathrm{AMC}$ released by muscle cytosol no.4 (the $6 \mu \mathrm{g}$ protein, $\boldsymbol{\square}$ in a) is shown without $(\mathbf{O})$ or with DEVD-cho $(50 \mathrm{nM})(\mathrm{O})$. Data truncation at 12 min for the in b was due to an over-scale recording of fluorescence 
albumin (BSA) additions. In this experiment, it can be seen that the muscle cytosols contained procaspases which equalled the procaspase contribution made by the addition of Jurkat S-100 cytosols. This increase in type-II caspase activity was not due solely to enhanced protein-protein interactions as BSA did not improve the diluted cytosol response $(+/+$, dilute). The specificity of this additional DEVD-AMC cleaving activity was tested using muscle cytosol no. 4 (at the $6 \mu \mathrm{g}$ protein level) added to the Jurkat S-100 activation. The specificity was assessed by using the active-site inhibitor of type-Il caspases, DEVDaldehyde (DEVD-cho), during the cleavage assay (Figure $2 b)$. The inhibitory, slow-binding kinetic profile which was generated is similar to that which has been observed when using purified caspase-3 with the same substrate-inhibitor combination. ${ }^{15}$ This suggests that the muscle cytosolcontributed DEVD-AMC cleavage activity was type-II caspase-derived and not due to non-specific cleavage. Based on these results, it can be concluded that the direct holoCyt-c/dATP-mediated activation of type-II caspases does not occur in human skeletal muscle S-100 cytosolic fractions. This is not due to the presence of an endogenous inhibitor of type-Il caspases in these cytosols.

In view of these findings, we investigated muscle cytosols for the presence of other protein components, namely the APAF-1 and procaspase- 9 proteins, which are vital to the initial activation mechanism by holo-Cyt-c/dATP. Immunoblot analysis of four enzymatically-evaluated muscle S-100 cytosols demonstrated the absence of an anti-APAF-1 immunoreactive $130 \mathrm{kDa}$ protein (Figure 3). ${ }^{11}$ This protein was clearly present in control cytosols from Jurkat T-cells (Figure 3 ). In contrast to the absence of APAF-1, there is a clear demonstration of immunoreactive procaspase- 3 and -9 and in these same muscle cytosols (Figure 3). Limited sample volume precluded Western analysis of APAF-1 in muscle cytosol no. 5 and no. 6, and for caspase-3 in cytosol no. 5 .

To further confirm the absence of APAF-1 protein in this tissue, we performed a kinetic analysis using RT-PCR for APAF-1 products on total RNA derived from a representative skeletal muscle biopsy. In the muscle sample, it can be seen that a 26 cycle number PCR produced a very weak $743 \mathrm{bp}$ band reflecting the APAF-1 cDNA-derived PCR

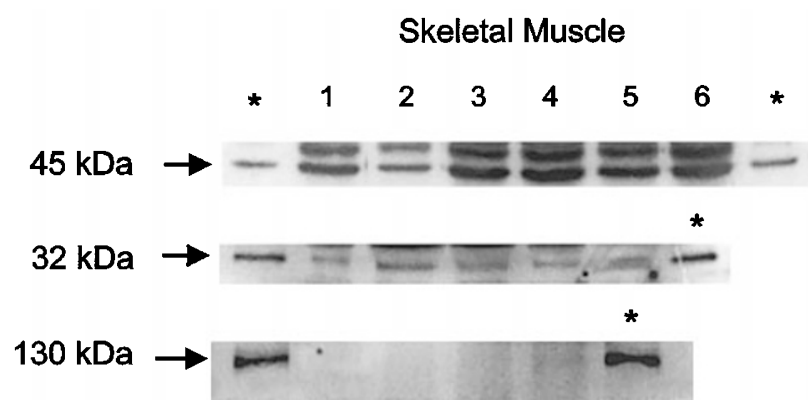

Figure 3 Western blot analysis showing the comparison of Jurkat (Jurkat=*) and muscle cytosol samples (no 1-6) for the procaspase-9 $(45 \mathrm{kDa})$, procaspase-3 (32 kDa) and the APAF-1 (130 kDa) proteins product (Figure 4). In addition, the presence of a PCRmediated cleavage product of $700 \mathrm{bp}$ is evident in almost all lanes of the muscle- but not the Jurkat-derived PCR products. The generation of this product may indicate that the APAF-1 template was limiting in this cDNA population and that excess PCR-product annealed to this template and became susceptible to the $5^{\prime}-3^{\prime}$ exonuclease activity of Taq polymerase. ${ }^{16}$ As a comparative control, a Jurkat T-cell cDNA-derived template generated a 743 bp PCR product at the 22 cycle number. The integrity of the cDNAs derived from both muscle and Jurkat cell samples was confirmed by the use of primers specific for glyceraldehyde-3phosphate dehydrogenase (G3PDH) which produced equal $983 \mathrm{bp}$ bands (Figure 4). Thus, this result suggests that the absence of APAF-1 protein in human skeletal muscle is due to a limiting number of APAF-1 transcripts. Our results using RT-PCR analysis confirm the observations of Zou et al which showed a very weak signal for APAF-1 in human skeletal muscle by Northern hybridisation. ${ }^{11}$ Indeed, it is possible that the signal obtained for APAF-1 mRNA in both reports is due to transcriptcontaining vasculature and white blood cells in the biopsy material.

\section{Discussion}

The absence of the APAF-1 protein and the suspect detection of APAF-1 mRNA, coupled with the lack of direct Cyt-c/dATPmediated activation of type-II caspase activity, suggests that human skeletal muscle may be refractory to certain mitochondrial-mediated events leading to apoptosis. This would occur due to a tissue-specific deficiency of one of the critical components necessary for the holoCyt-c/dATPmediated activation of procaspase-9. The absence of APAF-1 protein, in conjunction with an apparent low level of fibre-specific $C D 95^{17}$ and a tissue-specific expression of the ARC protein (apoptosis repressor with $\underline{\mathrm{CARD}}$ ), which inhibits the FasL/TNF-mediated activation of procaspase- $8,{ }^{18}$ suggests that normal human skeletal muscle is rather refractory to most of the major effector-mediated pathways of caspase activation presently understood. Indeed, one might argue that

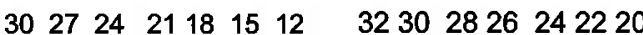

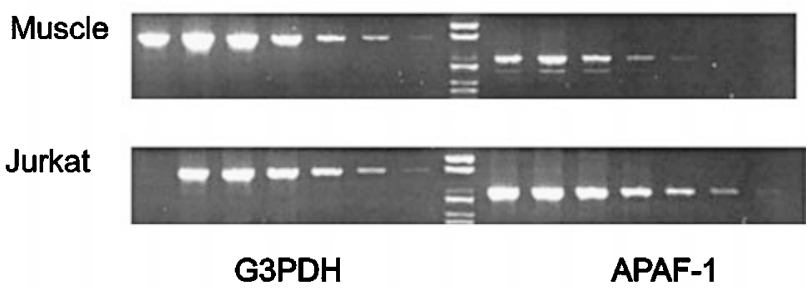

Figure 4 Ethidium bromide detection of PCR amplified products in a $1 \%$ agarose gel. Products were generated from muscle and Jurkat derivedcDNAs, top and bottom panels respectively. The G3PDH specific product of $983 \mathrm{bp}$ is shown on the left and the APAF-1 product $743 \mathrm{bp}$ is shown to the right. The numbering at the top represents the cycle number at which product was taken. The graphic representations of these two panels are derived from the same gel. Note: In lane 1 of the Jurkat/G3PDH the samples, template was omitted as a negative control 
an evolutionary advantage is gained by the downregulation of a mitochondria-dependent stimulation of apoptosis, both in view of the profusion of mitochondria in this tissue and by the demonstration that strenuous activity normally results in considerable acute mitochondrial swelling and/or degeneration. ${ }^{19}$ This suggestion of tissue-specific privilege does not preclude the possibility that an activation of procaspases may occur by another separate and currently undefined triggeringmechanism in skeletal muscle. However, the critical importance of a holocytochrome $c$-dependent regulation of an apoptosis inductive-mechanism in normal skeletal muscle is made less significant by our findings.

The downregulation of APAF-1 expression is accompanied by other mechanisms known to be involved in protection against the mitochondria-based release of holocytochrome $c$. For instance, it has been suggested that $\mathrm{Bcl}-\mathrm{XL} / \mathrm{Bcl}-2$ prevents holoCyt- $c$ expulsion from the mitochondrion thus preventing caspase activation. ${ }^{8,20}$ It is of interest to note that $\mathrm{Bcl}-2$ is expressed only at low levels in normal skeletal muscle, imparting some credence to the possibility that holoCyt- $c$ regulation is not critical as an antiapoptotic mechanism in this tissue. ${ }^{2}$ As there may be a minimal requirement for $\mathrm{Bcl}-2$ regulation of $\mathrm{Cyt}-\mathrm{c}$ in muscle, this tissue may provide an opportunity to reveal other nonapoptosis related Bcl-2-family member functions.

Recently, research into skeletal muscle mitochondria permeability transition pore (PTP) regulation suggests that the pharmacological modulation of PTP in this tissue may lead to numerous alterations in mitochondrial physiology that potentially contribute to cell death. ${ }^{21}$ In light of our present findings, the contribution of cytochrome $c$ release to direct pro-caspase activation will not be significant in muscle tissues. However, the activation of redox-stress mechanisms or mitochondrial-located procaspase-3 could contribute to cell death. ${ }^{22,23}$ Similarly, in rat cardiac myocytes the assumption has been made that cyt- $c$ gene activation by c-Jun may partially contribute to the progression of compensatory hypertrophy in the heart towards apoptosis. ${ }^{24}$ This assumption is also now less likely as the cardiac tissue Northern blots performed by Wang and co-workers ${ }^{11}$ also showed a weak APAF-1 mRNA signal similar to that seen in skeletal muscle. If enzyme activation results and Western analyses are consistent between skeletal muscle and cardiac myocytes, then only a minimal contribution by APAF-1 would be expected here as well. However, the difficulties in attaining normal cardiac tissue biopsies will preclude the confirmation of this speculation for at least the near future.

We are aware that several cytosolic, proteosomalcomplex and lysosomal-compartment proteases function in the diseased state of skeletal-muscle-wasting. However, these processes have been defined in diseases which have attained an 'equilibrium-status' of muscle-wasting. To our knowledge, there are no data which indicate that proteosomes or lysosomes function as early-inductive events during muscle-fibre loss. However, the function of calpain in skeletal muscle protein degradation has been predicted by several studies and is most recently described by Huang. ${ }^{25}$ This paper confirms that calplains are likely to be the protease-system which mediates the bulk of specific protein losses during muscle wasting disease. Unfortunately, the paper deals with ongoing proteolytic events in differentiated myoblast in culture and may not be representative of inductive-events in the tissue. On the other hand, Kinbara and coworkers, ${ }^{26}$ further reviewed by Suzuki, ${ }^{27}$ describes the presence of a muscle-specific calpain p94 which may be down-regulated during limbgirdle muscular dystrophy. This results in the onset of other proteolytic mechanisms and an ensuing muscle degradation. We find Kinbaras' finding extremely interesting as in separate studies, conducted in our laboratory, we have defined a specific role for calpain in non-apoptotic cultured cells which includes a novel interproteolytic regulation of procaspase-3 (unpublished observations). However, currently we have a limited understanding regarding the regulation of caspases in tissues. Therefore, we are hesitant to predict the involvement of the calpains in skeletal muscle apoptosis-induction events until further studies are performed.

Having defined that normal human skeletal muscle lacks the ability to commit to apoptotic events via correct assembly of the prerequisite apoptosome-activator, ${ }^{28}$ it is tantalising to speculate that situations involving muscle degeneration and/or alterations to fibre composition may involve temporary or permanent activation of this pathway, through up-regulation of APAF-1 expression. This is of particular relevance during the loss of muscle mass following bed-rest, ${ }^{29}$ in post-operative shock, ${ }^{30}$ in acute muscle injury and the 'over-training' syndrome in elite athletes and in situations of weightlessness experienced by astronauts. ${ }^{31}$ These possibilities await future investigation.

\section{Materials and methods}

\section{Subjects}

Skeletal muscle biopsies were obtained from seven healthy male volunteer subjects, aged 25-55. Prior to participation subjects were informed of the nature of the biopsy procedure and possible risks involved and each subject gave their consent. The study was approved by the Ethics Committee at the Karolinska Institute.

\section{Skeletal muscle biopsies}

Muscle samples $(60-110 \mathrm{mg})$ were obtained, at rest, from the lateral portion of the quadriceps femoris muscle (Vastus lateralis) by a standard biopsy technique. The tissues were rapidly frozen in liquid nitrogen and stored at $-80^{\circ} \mathrm{C}$ until further preparation. The numbering of muscle samples in Figures 2 and 3 refers to individual samples.

\section{Cell culture}

Jurkat cells (clone E6) were maintained in log-phase growth by regular passage using RPMI 1640 media (Sigma), 10\% heat-inactivated FCS, $2 \mathrm{mM} \mathrm{L}$-glutamine and $100 \mathrm{IU} / \mathrm{ml}$ penicillin and $50 \mu \mathrm{g} / \mathrm{ml}$ streptomycin.

\section{S-100 cytosol preparation}

Cytosols were prepared according to Liu et al ${ }^{10}$ using a S-100 buffer (20 mM HEPES-KOH (pH 7.5), $10 \mathrm{mM} \mathrm{KCl,} 1.5 \mathrm{mM} \mathrm{MgCl}$, 
$1 \mathrm{mM}$ Na-EDTA, $1 \mathrm{mM}$ Na-EGTA, $1 \mathrm{mM}$ DTT) supplemented with protease inhibitors $(100 \mu \mathrm{M}$ PMSF, $25 \mu \mathrm{g} / \mathrm{ml}$ acLLnL, $5 \mu \mathrm{g} / \mathrm{m}$ pepstatin-A, $10 \mu \mathrm{g} / \mathrm{ml}$ leupeptin, $2 \mu \mathrm{g} / \mathrm{ml}$ aprotinin). Jurkat cells were washed twice with ice-cold HBSS (phenol red-free) and resuspended in a four-times cell pellet volume of ice-cold S-100 buffer. Incubations were on ice for $40 \mathrm{~min}$ with frequent tube inversions for mixing. Cells were centrifuged at $1000 \times g$ for $10 \mathrm{~min}$ at $4^{\circ} \mathrm{C}$ and the resultant supernatants were recentrifuged at $10^{5} \times g$ for $30 \mathrm{~min}$ at $4^{\circ} \mathrm{C}$. Cytosols were tested for caspase-induction using either fresh or aliquoted samples which were stored at $-80^{\circ} \mathrm{C}$. Frozen muscle biopsies were homogenised in S-100 buffer using a plastic pestle in an eppendorf tube $(1.8 \mathrm{ml})$ at $1.5 \mathrm{~g} / \mathrm{ml}$ tissue. The homogenate was centrifuged at $1000 \times g$ for $10 \mathrm{~min}$ at $4^{\circ} \mathrm{C}$ and the resultant supernatants were recentrifuged at $3.0 \times 10^{4} \mathrm{~g}$ for $30 \mathrm{~min}$ at $4^{\circ} \mathrm{C}$. Cytosols were tested and stored as with Jurkat samples. Protein determinations were performed spectrophotometrically at $562 \mathrm{~nm}$ using the BCA (bicinchroninic acid) Protein Assay reagent from Pierce against a BSA standard.

\section{Type-II caspase activation and assessment}

Direct activation of type-II caspases was accomplished by the addition of cytochrome $c(400 \mathrm{nM}$, Sigma) and/or dATP (1 mM, Boehringer) added separately (e.g. \pm ) or together $(+/+)$ to $20 \mu$ of S-100 cytosols ( $2 \mu \mathrm{g} / \mathrm{l}$ protein) containing $1 \mathrm{mM}$ DTT on ice. Indirect activation involved the supplementation of the above activation with either S-100 buffer, muscle or Jurkat cytosols normalised for protein content and also containing DTT. Samples were incubated at $30^{\circ} \mathrm{C}$ for $60 \mathrm{~min}$ and immediately assayed for type-II caspase activity. Type-II caspase activity was determined, in duplicate, using $9 \mu \mathrm{l}$ (18 $\mu \mathrm{g}$ protein) of cytosol with $50 \mu \mathrm{l}$ of $50 \mu \mathrm{M}$ acDEVD-AMC (Peptide Research Inst.) prepared in a standard cleavage buffer (100 mM HEPES, 10\% sucrose, $0.1 \%$ CHAPS, $1 \mathrm{mM} \mathrm{DTT}$, pH 7.5). In a 96-well kinetic format fluorescent units (excitation $355 \mathrm{~nm}$, emissions $460 \mathrm{~nm}$ ) were averaged and converted into pmoles-AMC (-AMC standard). The maximum rate of $-\mathrm{AMC}$ release was determined empirically by evaluating linear slopes $\left(r^{2}>0.985\right)$ for pmoles/min over a $33 \mathrm{~min}$ period. Type-II caspase specificity was determined by including $50 \mathrm{nM}$ DEVD-aldehyde (DEVD-cho) within the $50 \mu \mathrm{M}$ DEVD-AMC substrate during the kinetic assay.

\section{Immunoblot analysis}

Samples were prepared by adding $5 \times$ Laemmli buffer to S-100 cytosols ( $2 \mu \mathrm{g} / \mu$ l protein) and boiling for $4 \mathrm{~min}$. Typically, $20 \mu \mathrm{g}$ of protein was loaded per lane and procaspase- $3,-9$ and APAF-1 protein separations were performed using $12 \%$ and $7.5 \%$ SDS-PAGE respectively. Western analysis of procaspase-3 were performed using an anti-p17 rabbit polyclonal antibody $(1: 7000)$ generously provided by Donald Nicholson, Merck-Frosst, Pointe-Claire Dorval, Quebec, Canada. The anti-caspase-9 (1:2000) and anti-APAF-1 $(1: 7000)$ antibodies were kindly provided by Xiaodong Wang, University of Texas Southwestern Medical Center at Dallas, Dallas, Texas. Detection of all primary antibodies was by use of a goat antirabbit-HRP (Pierce) and ECL (Amersham).

\section{RT - PCR analysis}

RNA extraction Total RNA from Jurkat cells was extracted using a RNeasy kit from QIAGEN, according to the manufacturers recommendations. The total RNA from muscle biopsies was extracted by a single-step method. ${ }^{32}$ One microgram of total RNA was reversetranscribed to CDNA in a total volume of $50 \mu$ and PCR amplification was performed using $5 \mu \mathrm{l}$ of cDNA for each reaction. The collection of PCR products was performed such that reactions were harvested following several different numbers of cycles to ensure that the exponential phase of amplification of each template could be analyzed. This allows for the direct comparison of muscle versus Jurkat templates for the G3PDH-mediated PCR as a positive control. APAF-1- or caspase-9-mediated PCR was performed in the same manner to assess the relative RNA levels in these tissues. The genespecific primer-pair used for amplification of APAF-1 gave a PCR product of 743 bp in length ( $5^{\prime}$; CCCACTCAACAGCAAAGAGC and 3 ; TGGAAGAACAGGTACGATTG) and for Caspase-9 gave a PCR

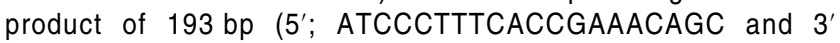
TATCTAGTTTGCCCACACCC).

DNA molecular weight markers were from Boehringer Mannheim catalogue number 1062590.

\section{Acknowledgements}

The authors would like to acknowledge financial support from the Swedish Medical Research Council (to I.A.C. and S.O.) and the Swedish Center for Sports Research (to I.A.C.). We also acknowledge the support of K. Söderlund of the department of Physiology and Pharmacology. The authors with to thank A. Samali, B. Fadeel, B. Zhivotovsky and C.E. Burgess for their suggestions and critical reading of the manuscript.

\section{References}

1. DeLong MJ (1998) Apoptosis: a modulator of cellular homeostasis and disease states. Ann. NY Acad. Sci. 15: 82-90

2. Tews DS and Goebel HH (1997) Apoptosis-related proteins in skeletal muscle fibers of spinal muscular atrophy. J. Neuropathol. and Experimental Neurol. 56: $150-156$

3. Sandri M, Podhorska-Okolow M, Geromel V, Rizzi C, Arslan P, Franceschi C and Carraro U (1996) Sudden spontaneous exercise increases myonuclear ubiquitination and apoptosis of dystrophin deficient muscle. Basic \& Appl. Myology 6: 285-289.

4. Allen DL, Monke SR, Talmadge RJ, Roy RR and Edgerton VR(1995) Plasticity of myonuclear number in hypertrophied and atrophied mammalian skeletal muscle fibers. J. Appl. Physiol. 78: 1969-1976

5. Allen DL, Linderman JK, Roy RR, Bigbee AJ, Grindeland RE, Mukku V and Edgerton VR (1997) Apoptosis: A mechanism contributing to remodeling of skeletal muscle in response to hindlimb unweighting. Am. J. Physiol. 273: 579587

6. Zhivotovsky B, Burgess DH, Vanags DM and Orrenius S (1997) Involvement of cellular proteolytic machinery in apoptosis. Biochem. Biophys. Res. Commun. 230: $481-488$

7. Black SC, Huang JQ, Rezaiefar P, Radinovic S, Eberhart A, Nicholson DW and Rodger IW (1998) Co-localization of the cysteine protease caspase-3 with apoptotic myocytes after in vivo myocardial ischemia and reperfusion in the rat. J. Mol. and Cell. Card. 30: 733-742

8. Kluck RM, Bossy-Wetzel E, Green DR and Newmeyer DD (1997) The release of cytochrome $c$ from mitochondria: a primary site for $\mathrm{Bcl}-2$ regulation of apoptosis. Science 275: $1132-1136$

9. Yang J, Liu X, Bhalla K, Kim CN, Ibrado AM, Cai J, Peng TI, Jones DP and Wang X (1997) Prevention of apoptosis by bcl-2: release of cytochrome from mitochondria blocked. Science 275: 1129-1131

10. Liu X, Kim NC, Yang J, Jemmerson R and Wang X (1996) Induction of apoptotic program in cell-free extracts: requirement for dATP and cytochrome c. Cell 86 : $147-157$

11. Zou H, Henzel WJ, Liu X, Lutschg A and Wang X (1997) Apaf-1 a human protein homologous to $\mathrm{C}$. elegans CED-4, participates in cytochrome c-dependent activation of caspase-3. Cell 90: 405-413

12. Li P, Nijhawan D, Budihardjo I, Srinivasula SM, Ahmad M, Alnemri ES and Wang $X$ (1997) Cytochrome $c$ and dATP-dependent formation of Apaf-1/caspase-9 complex initiates an apoptotic protease cascade. Cell 91: 479-489 
13. Srinivasula SM (1996) The Ced-3/interleukin 1 beta converting enzyme-like homolog Mch6 and the lamin-cleaving enzyme Mch2alpha are substrates for the apoptotic mediator CPP32. J. Biol. Chem. 271: 27099-27106

14. Hampton MB, Zhivotovosky B, Slater AFG, Burgess DH and Orrenius S (1998) Importance of the redox state of cytochrome $c$ during caspase activtion in cytosolic extracts. Biochem. J. 329: 95-99

15. Nicholson DW, Ali A, Thornberry NA, Vaillancourt JP, Ding CK, Gallant M, Gareau Y, Griffin PR, Labelle M, Lazebnik YA et al (1995) Identification and inhibition of the ICE/CED-3 protease necessary for mammalian apoptosis. Nature 376: $37-43$

16. Holland PM, Abramson RD, Watson R and Gelfand DH (1991) Detection of specific polymerase chain reaction product by utilizing the $5^{\prime}-3^{\prime}$ exonuclease activity of thermus aqaticus DNA polymerase. Proc. Natl. Acad. Sci. 88: 7276 7280

17. Sahashi K, Ibi T and Ling J (1995) Immunostaining of anti-Fas IgG1 antibody in diseased human muscle. Rhinsho Shinkeigaku - Clin. Neuro. 35: 764-769

18. Koseki T, Inohara N, Chen S and Núñez G (1998) ARC, an inhibitor of apoptosis expressed in skeletal muscle and heart that interacts selectively with caspases Proc. Natl. Acad. Sci. 95: 5156-5160

19. Zamora AJ, Tessier F, Marconnet P, Margaritis I and Marini JF (1995) Mitochondria changes in human muscle after prolonged exercise, endurance training and selenium supplementation. Eur. J. Appl. Physiol. 71: 505-511

20. Bossy-WetzelE, NewmeyerDD and Green DR (1998) Mitochondrial cytochrome $c$ release in apoptosis occurs upstream ofDEVD-specific caspase activation and independently of mitochondrial transmembrande depolarization. EMBO J. 17: $37-49$

21. Fontaine E, Eriksson O, Ichas F and Bernard P (1998) Regulation of the permeability transition pore in skeletal muscle mitochondria. Modulation by electron flow through the respiratory chain complexi. J. Biol. Chem. 273: 12662 12668
22. Reed JC (1997) Cytochrome $c$ : can't live without it. Cell 91: 559-562

23. Mancini M, Nicholson DW, Roy S, Thornberry NA, Peterson EP, Casciola-Rosen LA and Rosen A (1998) The caspase-3 precursor has a cytosolic and mitochondrial distribution: Implications for apoptosis signalling. J. Cell. Biol. 140: $1485-1495$

24. Xia Y, Buja M and McMillin JB (1998) Activation of the cytochrome $c$ gene by electrical stimulation in neonatal rat cardiac myocytes. Role of NRF-1 and c-Jun. J. Biol. Chem. 273: $12593-12598$

25. Huang $\mathrm{J}$ and Forsberg NE (1998) Role of calpain in skeletal-muscle protein degradation. P.N.A.S. 95: 12100-12105

26. Kinbara K, Sorimachi H, Ishiura S and Susuki K (1998) Skeletal muscle-specific calpain, p94: structure and physiological function. Biochem. Pharmacol. 56 $415-420$

27. Suzuki K and Sorimachi H (1998) A novel aspect of calpain activation. FEBS Letters 433: 1 -4

28. Hengartner MO (1997) Apoptosis. CED-4 is a stranger no more. Nature 388 $714-715$

29. Berg HE, Larsson L and Tesch PA (1997) Lower limb skeletal muscle function after 6 wk of bed rest. J. Appl. Physiol. 82: 182-188

30. Petersson B, Hultman E, Andersson K and Wernerman (1995) Human skeletal muscle protein: effect of malnutrition, elective surgery and total parenteral nutrition. J. Clin. Sci. 88: 479-484

31. Booth FW and Criswell DS (1997) Molecular events underlying skeletal muscle atropy and the development of effective countermeasures. Int. J. Sports Med. 18: $265-269$

32. Chomczynski Pand SacchiN (1987) Single-step method of RNA isolation by acid guanidinium thiocyanate-phenol-chloroform extraction. Anal. Biochem. 162: $156-159$ 